\title{
Attributes of silica treatment on strength, physical properties and consolidation rates of fluid fine tailings
}

\author{
RH Moffett E.I. DuPont, USA
}

\begin{abstract}
Management of fluid fine tailings (FFT) is an ongoing challenge to the mining industry. To meet this challenge, in situ polymerisation of silica has been proposed as a low cost and practical method for treatment of fluid fine tailings. Silica polymerisation modifies the rheological properties of FFT, imparting significant yield strength and consolidation benefits which are maintained throughout the dewatering process. In situ polymerisation creates a continuous silica network within the fluid phase of the FFT that allows unrestricted water movement but prevents fines migration and blinding of drainage boundaries. Silica treated FFT has been demonstrated to enable self-weight consolidation. More rapid consolidation rates can be achieved through increased effective stress generated by thicker lifts and surcharge loading made practical by the high strength and enhanced erosion resistance provided by silica treatment.
\end{abstract}

This paper will provide a general overview of how in situ polymerisation functions and its effect on FFT physical properties and consolidation rates.

\section{Introduction}

Production of FFT is often a necessary but undesirable consequence of many mining techniques. Treatment and environmentally sound deposition of FFT presents a challenging prospect for mining companies. Chemical treatment of FFT to facilitate dewatering is practiced by many mine operators as a method to stabilise and consolidate FFT. Coagulants and flocculants are the principle chemicals used to facilitate dewatering. Achieving consistent and reproducible dewatering and consolidation rates using traditional chemical treatment is often difficult as FFT solids concentration, mineralogy and specific surface area all affect flocculant performance.

In situ polymerisation of silica within the water phase of FFT has been proposed as a simple, robust process for treatment of FFT (Moffett 2010). A silica source (Particlear ${ }^{\mathrm{TM}}$ ) is added to the tailings along with an activator that initiates silica polymerisation to form a continuous, three-dimensional network of nano-sized silica particles within the water phase of the tailings. The silica network entraps FFT solids particles while retaining porosity so as to allow water to pass through the void space of the FFT as easily as it would without the presence of silica (Sobkowicz 2013). The formation of the silica network links the FFT solid particles together to permit transmission of stress from particle-to-particle, in effect creating a synthetic soil (Moore 2013). The process is highly analogous to increasing soil strength by chemical grouting (Karol 2003) but is practiced at much lower silica dose rates. Sobkowicz (2013) notes the concept behind the use of Particlear ${ }^{\mathrm{TM}}$ for treatment of FFT is very different from that of flocculants or coagulants. Sobkowicz also notes the silica is dosed based on the water rather than the mineral content of the FFT. This dosing convention is continued in this paper. Dose rates are reported as wt\% SiO2 relative to the water in the FFT.

\section{Tailings sample characterisation}

Samples of fluid fine tailings were obtained from two different oil sands mines. General physical properties of the tailings are shown in Table 1. Particle size distribution was determined by static light scattering using a Malvern Instruments Mastersizer 2000. For purposes of this paper, sand to fine ratio is defined as the volume ratio of particles $>44$ microns in diameter relative to those particles $<44$ microns. Tailings solids 
mineralogy was determined by $\mathrm{x}$-ray diffraction (XRD). Major cations dissolved within the pore water of the tailings were determined by inductively coupled plasma (ICP).

Table 1 FFT characterisation

\begin{tabular}{|c|c|c|c|c|c|c|c|c|c|}
\hline \multirow[b]{2}{*}{ Sample } & \multirow[b]{2}{*}{$\begin{array}{c}\text { Tailings } \\
\text { type }\end{array}$} & \multirow[b]{2}{*}{ Source } & \multirow{2}{*}{$\begin{array}{c}\text { wt\% solids } \\
\text { (includes } \\
\text { bitumen) }\end{array}$} & \multirow[b]{2}{*}{ pH } & \multirow[b]{2}{*}{$\begin{array}{c}\text { SpG } \\
\text { (g/cc) }\end{array}$} & \multicolumn{4}{|c|}{ Particle size distribution $(\mu \mathrm{m})$} \\
\hline & & & & & & $D(0.1)$ & $D(0.5)$ & $D(0.9)$ & SFR \\
\hline A & $\begin{array}{l}\text { Mature } \\
\text { fine } \\
\text { tailings }\end{array}$ & $\begin{array}{l}\text { Alberta } \\
\text { oil Sands }\end{array}$ & 39.5 & 7.7 & 1.26 & 1.7 & 10.8 & 46.9 & 0.14 \\
\hline \multirow[t]{2}{*}{ B } & $\begin{array}{l}\text { Mature } \\
\text { fine } \\
\text { tailings }\end{array}$ & $\begin{array}{l}\text { Alberta } \\
\text { oil sands }\end{array}$ & 30 & 7.2 & 1.21 & 1.6 & 8.4 & 36.6 & 0.06 \\
\hline & \multicolumn{4}{|c|}{$\begin{array}{l}\text { Solids composition } \\
\text { Primary clays (wt\%) }\end{array}$} & \multicolumn{5}{|c|}{ Major cations dissolved in pore water (ppm) } \\
\hline Sample & $\begin{array}{l}\text { SiO2 } \\
\text { (wt\%) }\end{array}$ & Kaolinite & Illite & Impurities & $\mathrm{Ca}$ & K & Mg & $\mathrm{Na}$ & $\mathbf{S}$ \\
\hline A & 64.4 & 17.9 & 3.5 & Balance & 15 & 17 & 9 & 379 & 3 \\
\hline B & 58 & 17 & 6 & Balance & 5 & 8 & 3 & 418 & 12 \\
\hline
\end{tabular}

\section{$3 \quad$ FFT physical properties modification by silica}

\subsection{Tailings viscosity}

The viscosity of mature fine tailings (MFT) ' $A$ ' was determined using a Brookfield DV III+ rheometer utilising a vaned spindle rotating at $250 \mathrm{rpm}$ (Figure 1 ).

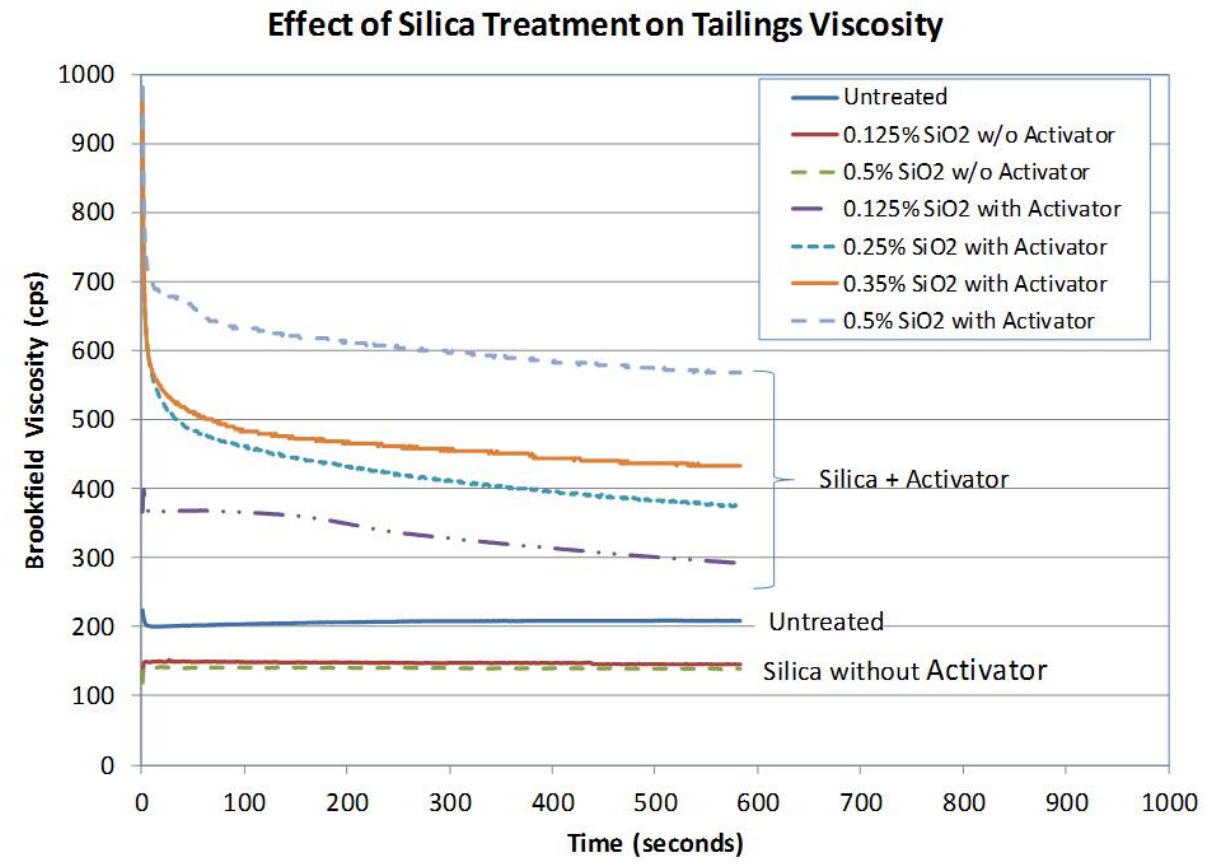

Figure 1 Effect of silica treatment on MFT 'A' viscosity 
The rheometer was connected to a PC running Brookfield's Rheocalc software (Brookfield Engineering Laboratories, Inc. n.d.). Figure 1 shows how the addition of the silicate solution alone (no activator) reduces the viscosity of the MFT. Upon addition of the activator (Figure 1) the viscosity only slightly increases above that seen for the untreated MFT. Continual shear from the rheometer spindle is seen to reduce the apparent viscosity of the silica plus activator treated samples.

\subsection{Yield strength}

MFT ' $A$ ' was treated with varying levels of silica. Peak yield strength was determined using again the Brookfield rheometer and vaned spindle now rotating at $0.1 \mathrm{rpm}$. Figure 2 shows how silica addition can dramatically increase the peak yield strength of the MFT within a few hours of treatment without requiring the loss of water.

\section{Development of Yield Strength as a Function of Time - No Water Loss}

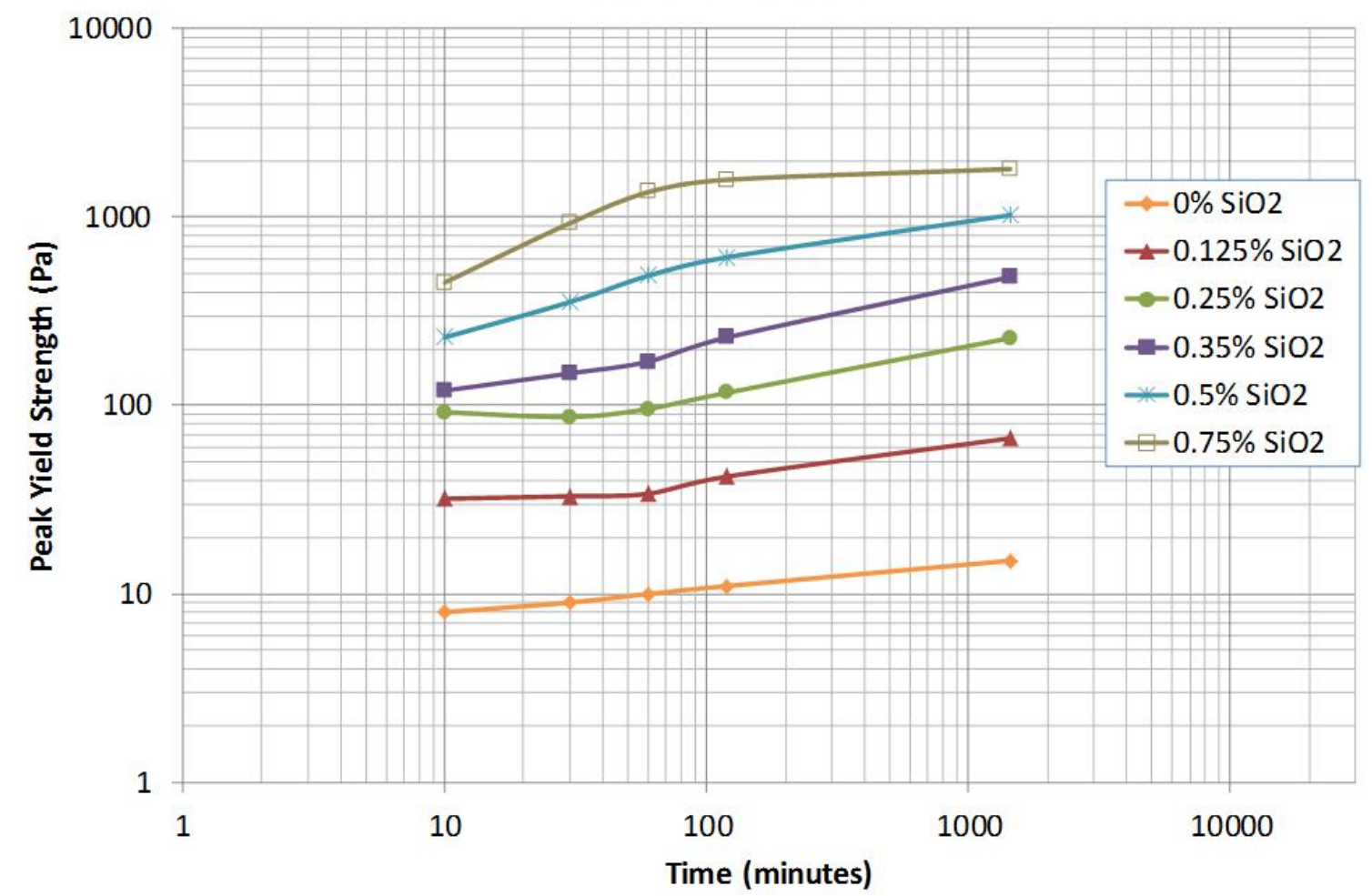

Figure 2 Effect of silica dose on the yield strength of MFT 'A' without water loss

Treated MFT ' $A$ ' samples shown in Figure 2 were dewatered under a vertically applied load at varying stress levels. The peak yield strengths as a function of solids content of the dewatered samples are shown in Figure 3. Also shown in Figure 3 are the yield strength of MFT ' $A$ ' treated with $500 \mathrm{~g} / \mathrm{t}$ of a high molecular weight anionic polyacrylamide (APAM) dewatered under the same conditions. As can be seen in Figure 3 the silica treatment provides a yield strength advantage throughout the entire dewatering process over the untreated or APAM treated samples. 


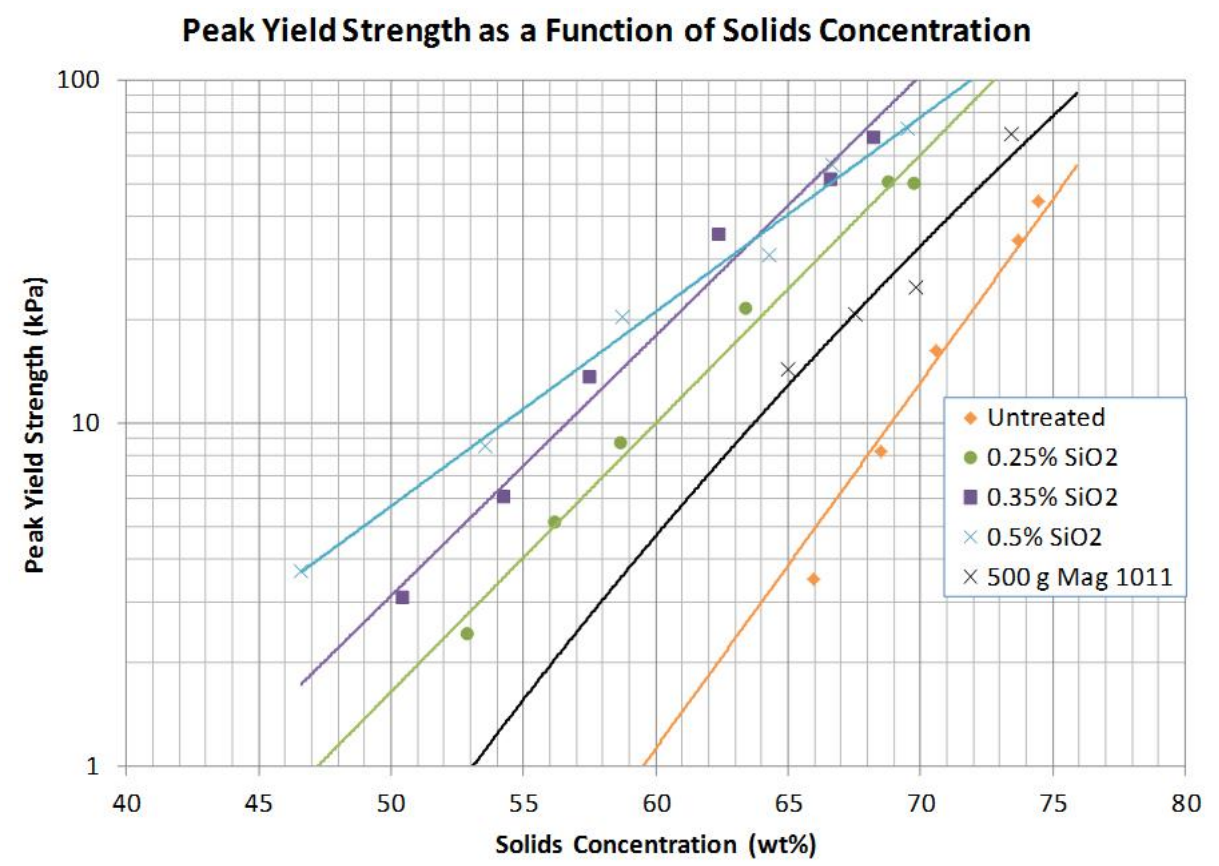

Figure 3 Yield strength of silica and APAM treated MFT 'A' versus solids concentration

Remoulded strength of the samples in Figure 3 was assessed by increasing the speed of the rheometer spindle used for the peak yield strength determination from 0.1 to $1 \mathrm{rpm}$. Ten revolutions were conducted at the higher speed followed by a one minute rest period. The rheometer was then restarted at $0.1 \mathrm{rpm}$ and the peak (remoulded) yield strength was re-measured. This procedure was repeated at $10 \mathrm{rpm}$ in a different location in the sample. The average of the remoulded strengths after shearing at 1 and $10 \mathrm{rpm}$ are shown in Figure 4. The APAM treated MFT has essentially the same yield strength as the untreated sample whereas the silica treated MFT samples maintain significantly higher yield strength throughout the entire dewatering process.

Avg. Remolded Yield Strength as a Function of Solids Conc.

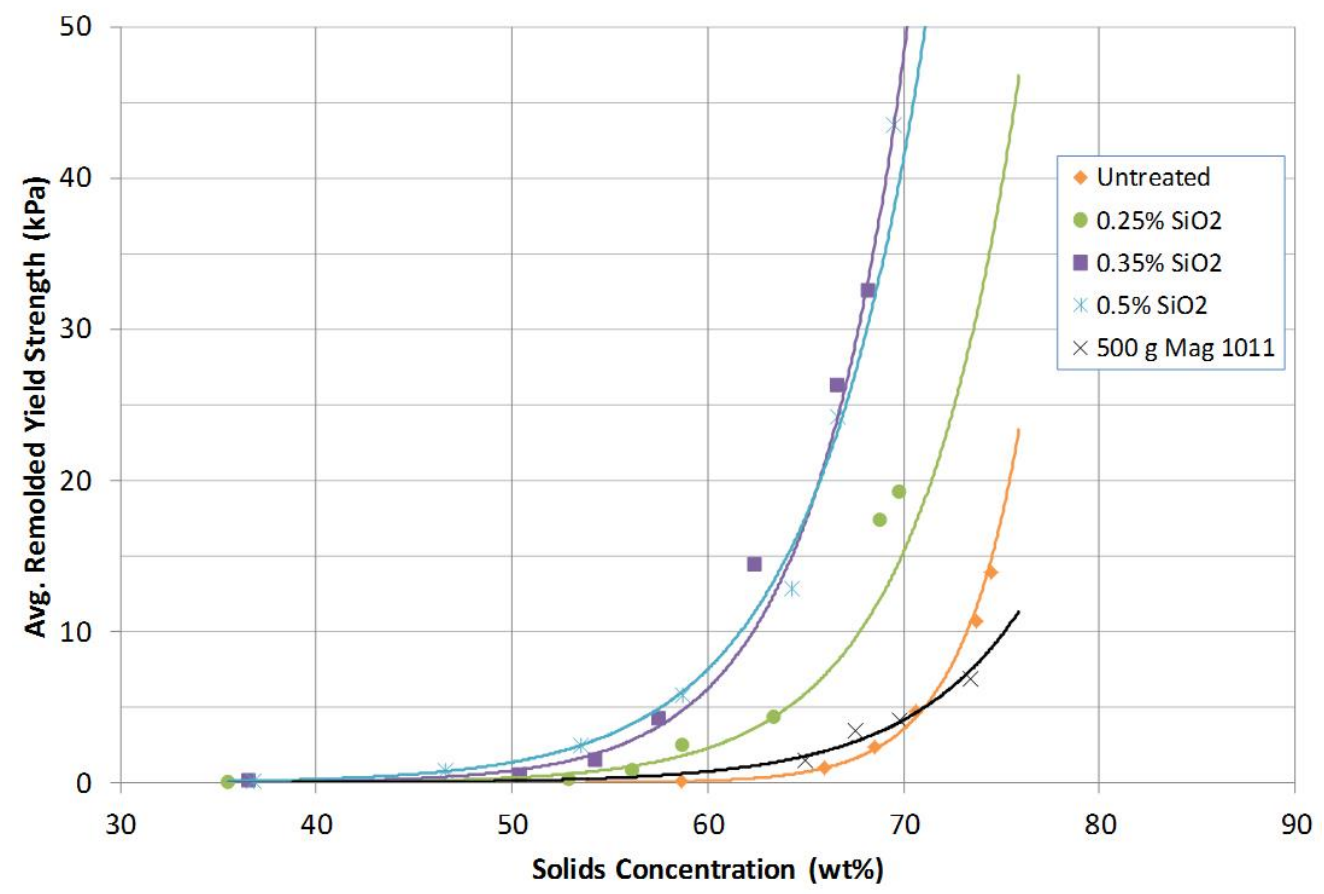

Figure 4 Remoulded yield strength of silica and APAM treated MFT 'A' versus solids concentration 


\subsection{Discharge flow properties}

As discussed in Sections 3.1 and 3.2, silica treatment immediately modifies FFT viscosity and ultimately creates a silica network within the water phase of the FFT increasing its yield stress. During FFT deposition, development of yield stress and dissipation of shear will in due course arrest FFT flow (Tilton 2013). By varying the reaction conditions during silica treatment, both the initial viscosity and the rate of increase in yield strength can be varied so as to affect the 'flowability' of FFT. To assess this affect, MFT 'B' was continuously discharged at $180 \mathrm{~L} / \mathrm{min}$ on to a $0.51 \mathrm{~m}$ wide stainless steel flume set at a $1.5 \%$ slope. After 75 min untreated MFT ' $B$ ' flowed approximately $2.5 \mathrm{~m}$ down the slope from point of discharge. The flow distance after $75 \mathrm{~min}$ for MFT 'B' treated with $0.5 \%$ silica $(180 \mathrm{ml} / \mathrm{min}$ discharge rate) was found to be controllable between 0.7 and $3.7 \mathrm{~m}$ depending upon the reaction conditions selected (Figure 5). Figure 6 displays the distance the FFT travelled down the flume as a function of time. Three depth measurements across the flume were taken each $0.3 \mathrm{~m}$ down the flume length. The average depth versus the distance from point of discharge on the flume is plotted in Figure 6 . The data shows silica treatment has the ability to significantly modify flow distance and stacking angle of FFT.

Untreated

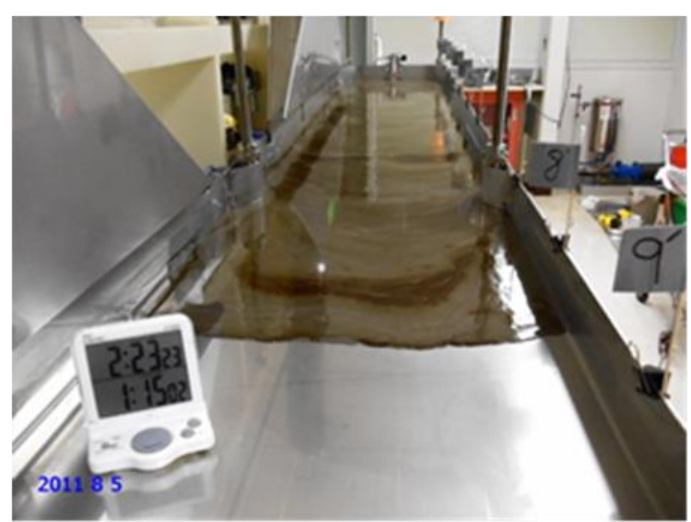

0.5\% SiO2 Rapid Set

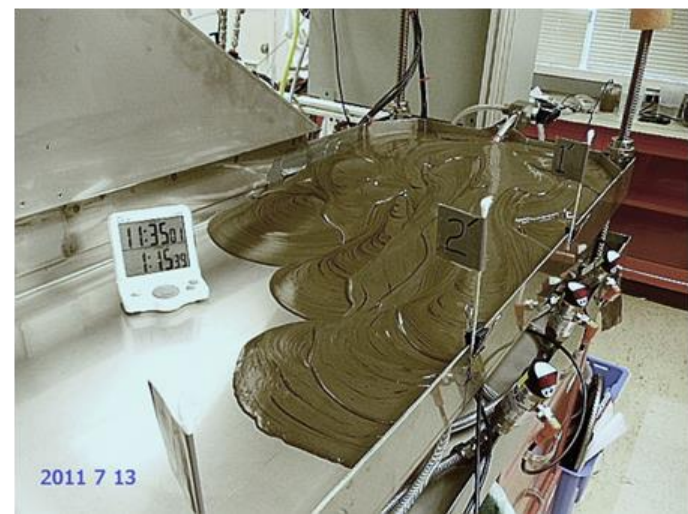

0.5\% SiO2 Standard Conditions

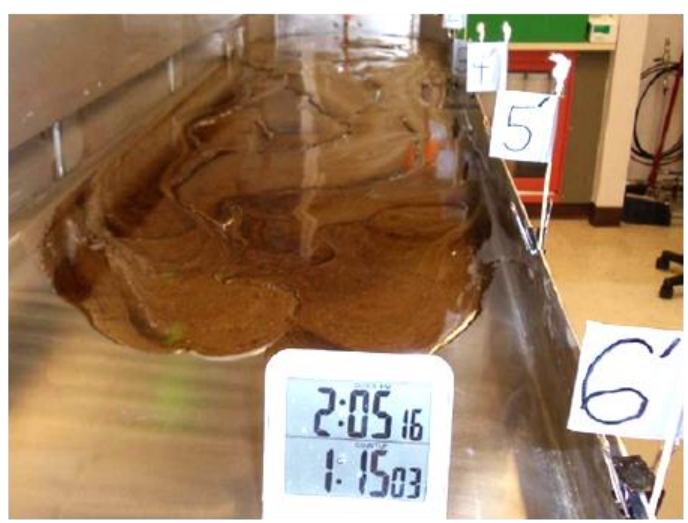

0.5\% SiO2 Delay Technology

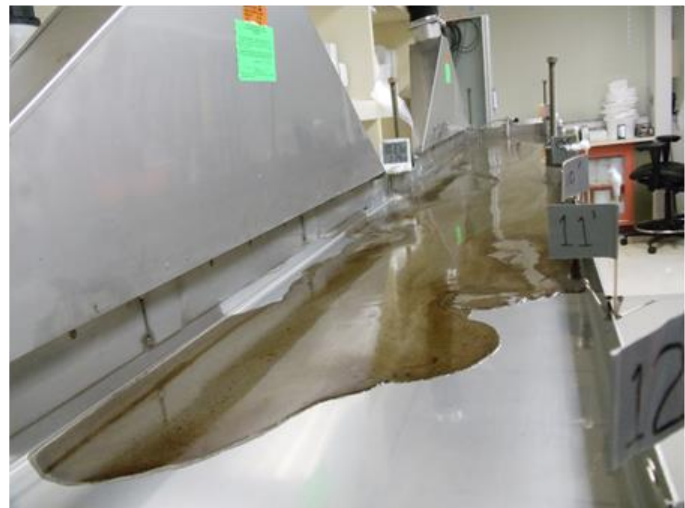

Figure 5 Laboratory flume tests demonstrating ability of silica treatment to modify FFT flow properties 

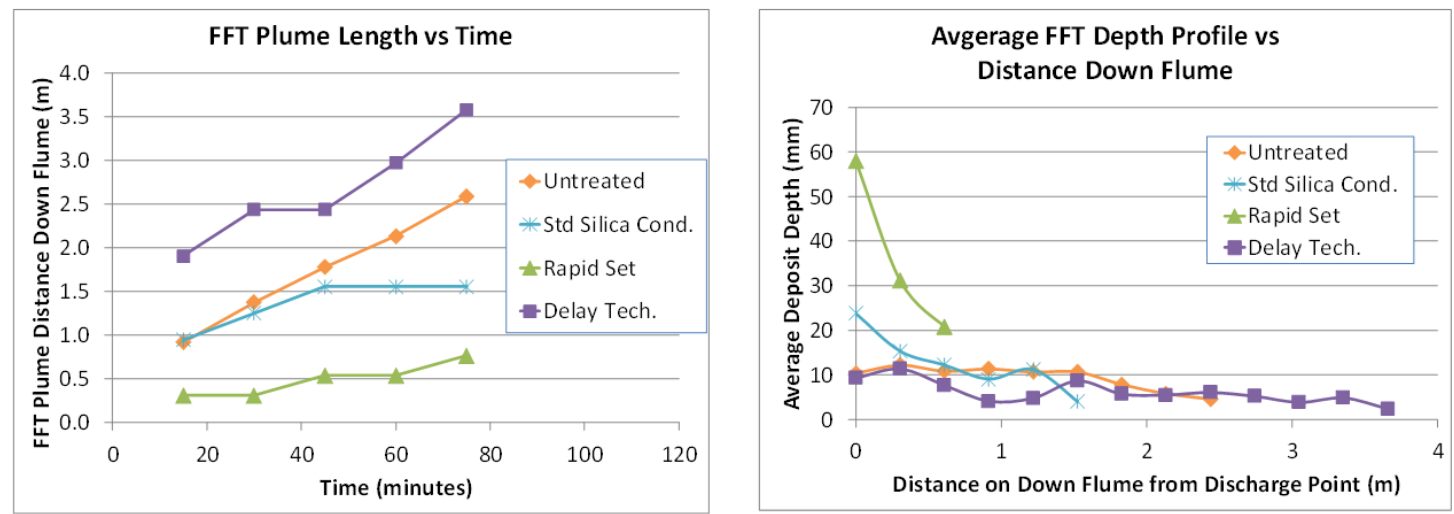

Figure 6 Silica treated FFT plume length and deposit profile on laboratory flume

\subsection{Compressibility and hydraulic conductivity}

The compressibility and hydraulic conductivity of MFT ' $A$ ' was determined in large strain consolidometer experiments following the procedure described by Moore (2013). Figure 7 shows silica treatment has no measurable impact on hydraulic conductivity at any given void ratio. Figure 8 shows however that silica treatment reduces MFT compressibility, particularly at low levels of effective stress. The result is that FFT treated with silica maintains a higher hydraulic conductivity at a given level of effective stress (Figure 9). Higher hydraulic conductivity should be expected to result in faster consolidation rates and is confirmed in Section 3.5 of this paper.

\section{Hydraulic Conductivity vs Void Ratio}

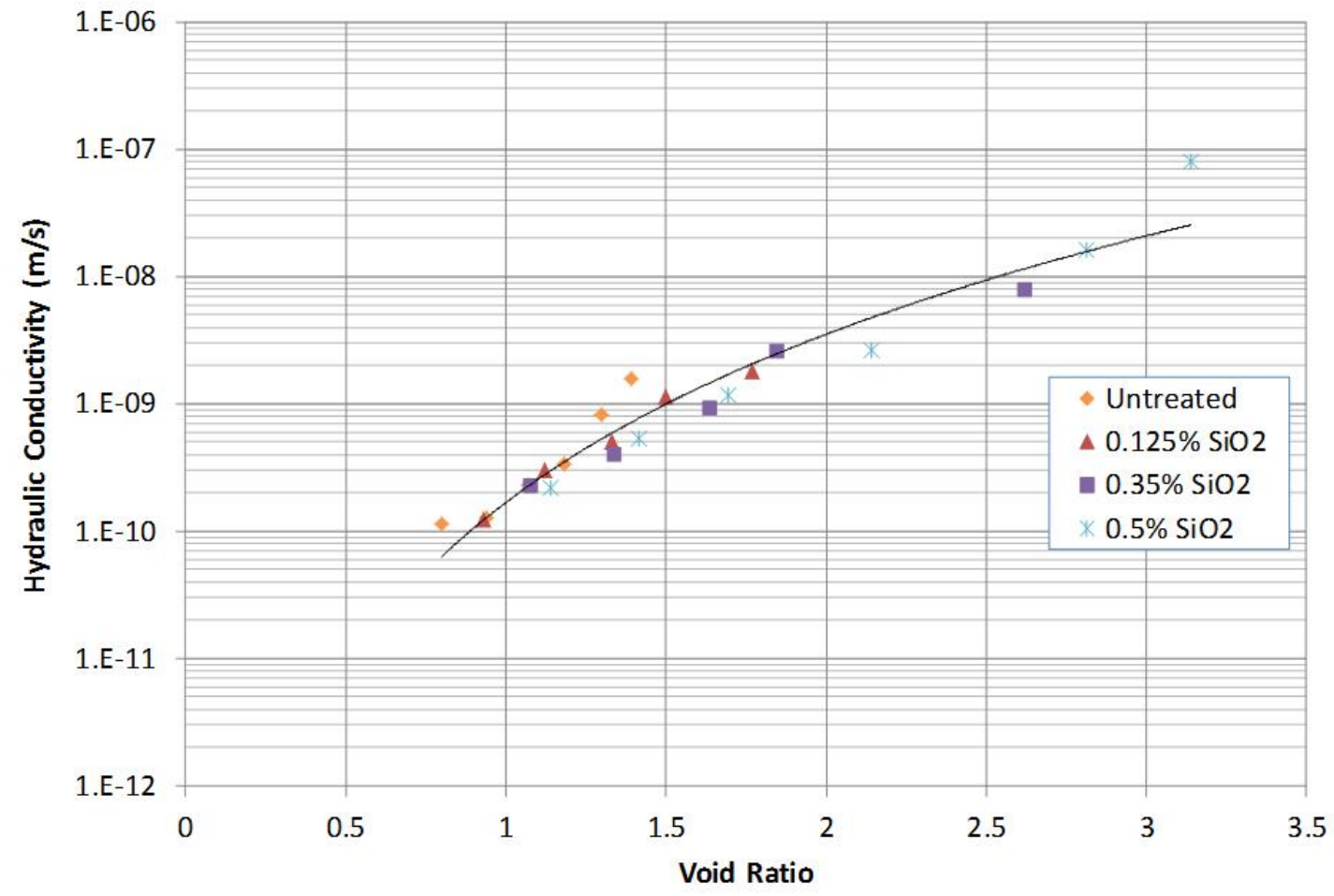

Figure 7 Hydraulic conductivity versus void ratio of silica treated MFT 'A' 


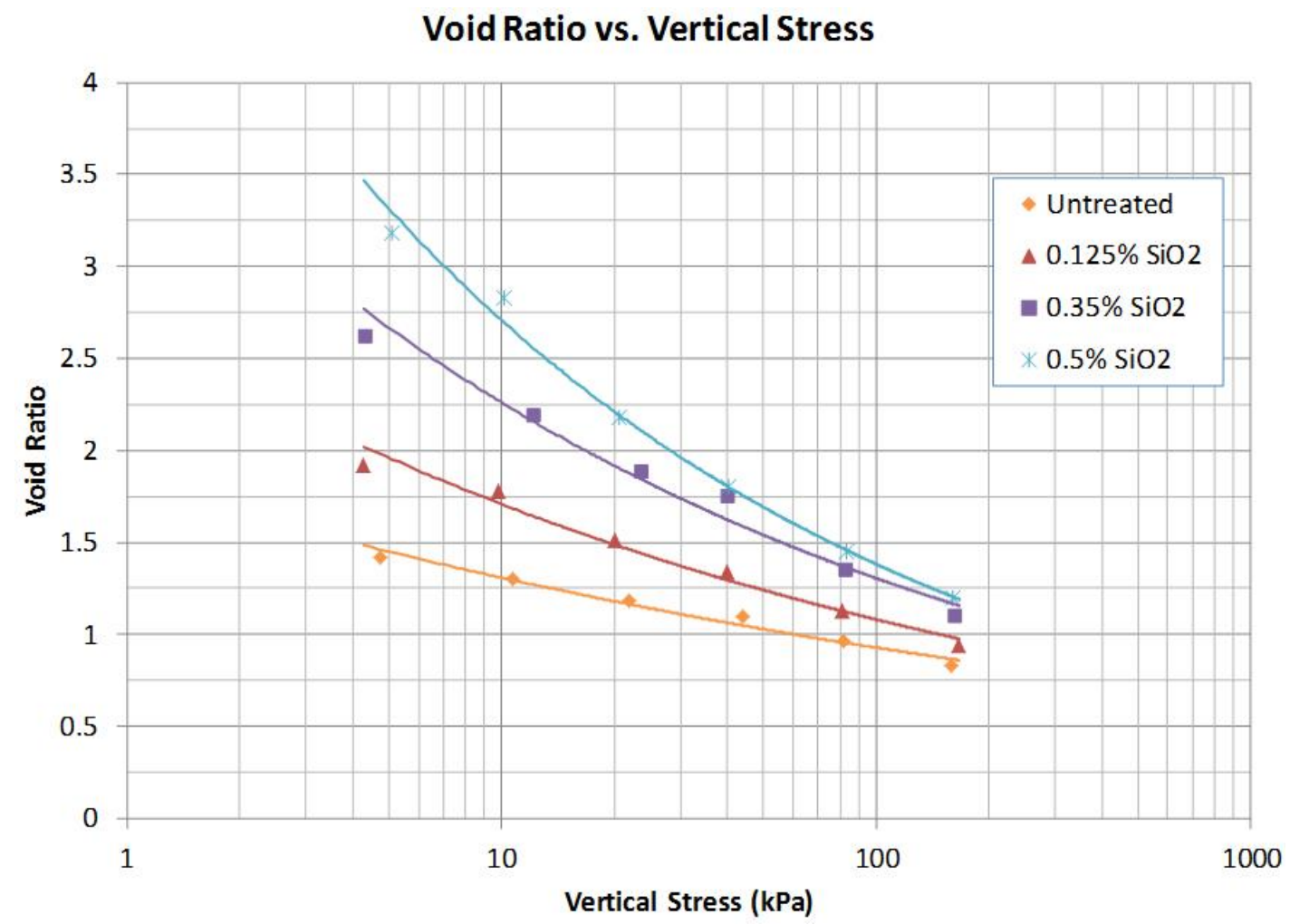

Figure 8 Void ratio versus vertical effective stress of silica treated MFT 'A' 


\section{Hydraulic Conductivity vs Vertical Stress}

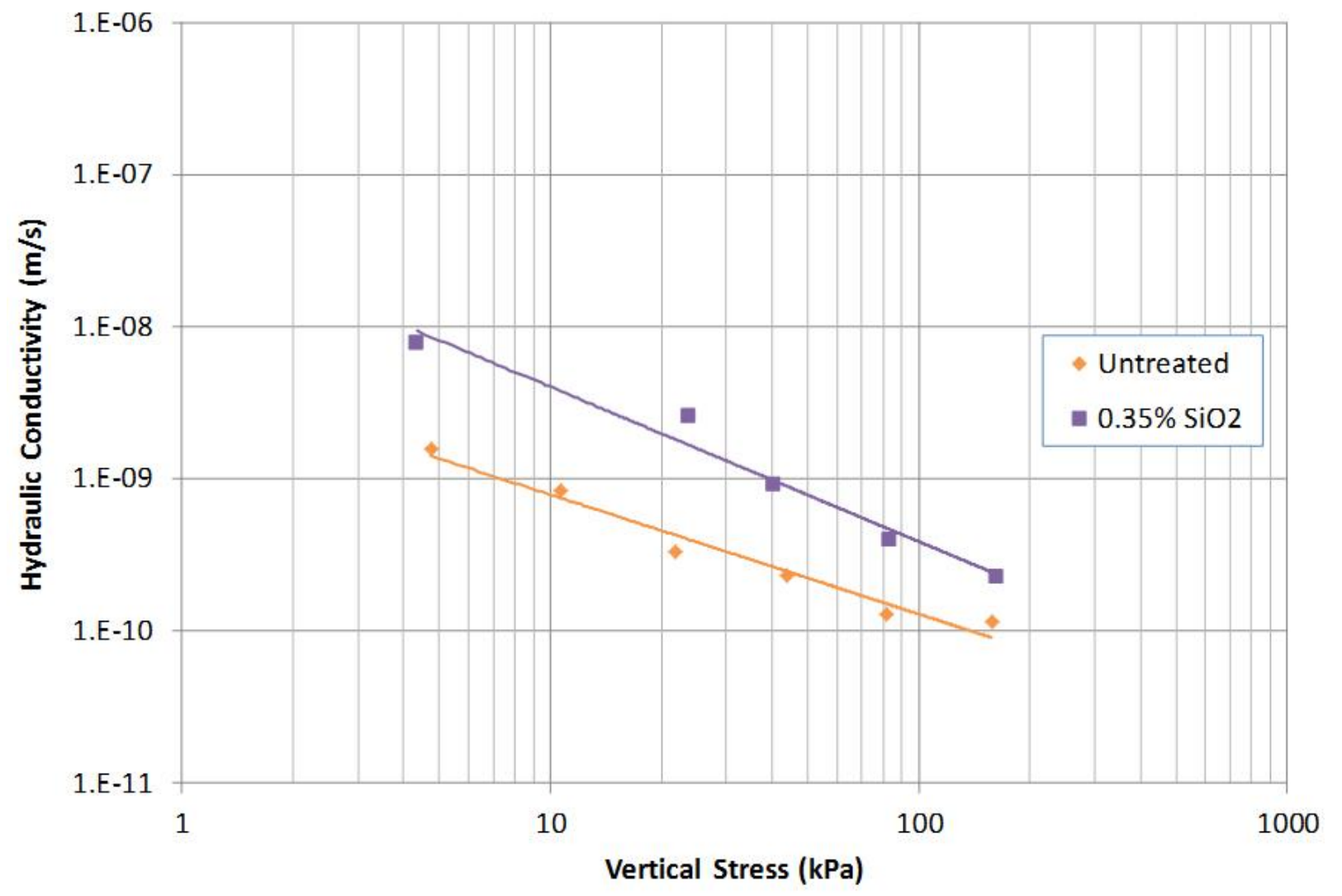

Figure 9 Hydraulic conductivity versus vertical effective stress of untreated and silica treated MFT ' $A$ '

\subsection{Consolidation rate}

The consolidation rate of MFT ' $A$ ' treated with either silica or APAM was assessed using a simple consolidation cell (Figure 10). 1,188 g of treated MFT ' $A$ ' samples (426 g solids) were loaded into the $9.73 \mathrm{~cm}$ diameter cell. The samples were allowed to dewater for 24 hours before insertion of the floating piston and initiation of the compressive dewatering experiment. Any water released to the surface of the sample during this 24 hour period was removed prior to the start of the compressive dewatering experiment. A constant vertical stress between 10 and $200 \mathrm{kPa}$ was applied to individual samples using an air cylinder. The reduction in the height of each sample was recorded with time.

To compare consolidation rates between samples the total reduction in height of each sample was determined. The time required to reach $90 \%$ of total consolidation under compressive force was determined from the displacement versus time records. Figure 10 shows the silica treated samples consolidate faster than either the APAM treated or untreated MFT samples. 
Time to $90 \%$ Consolidation (hrs) versus Effective Stress

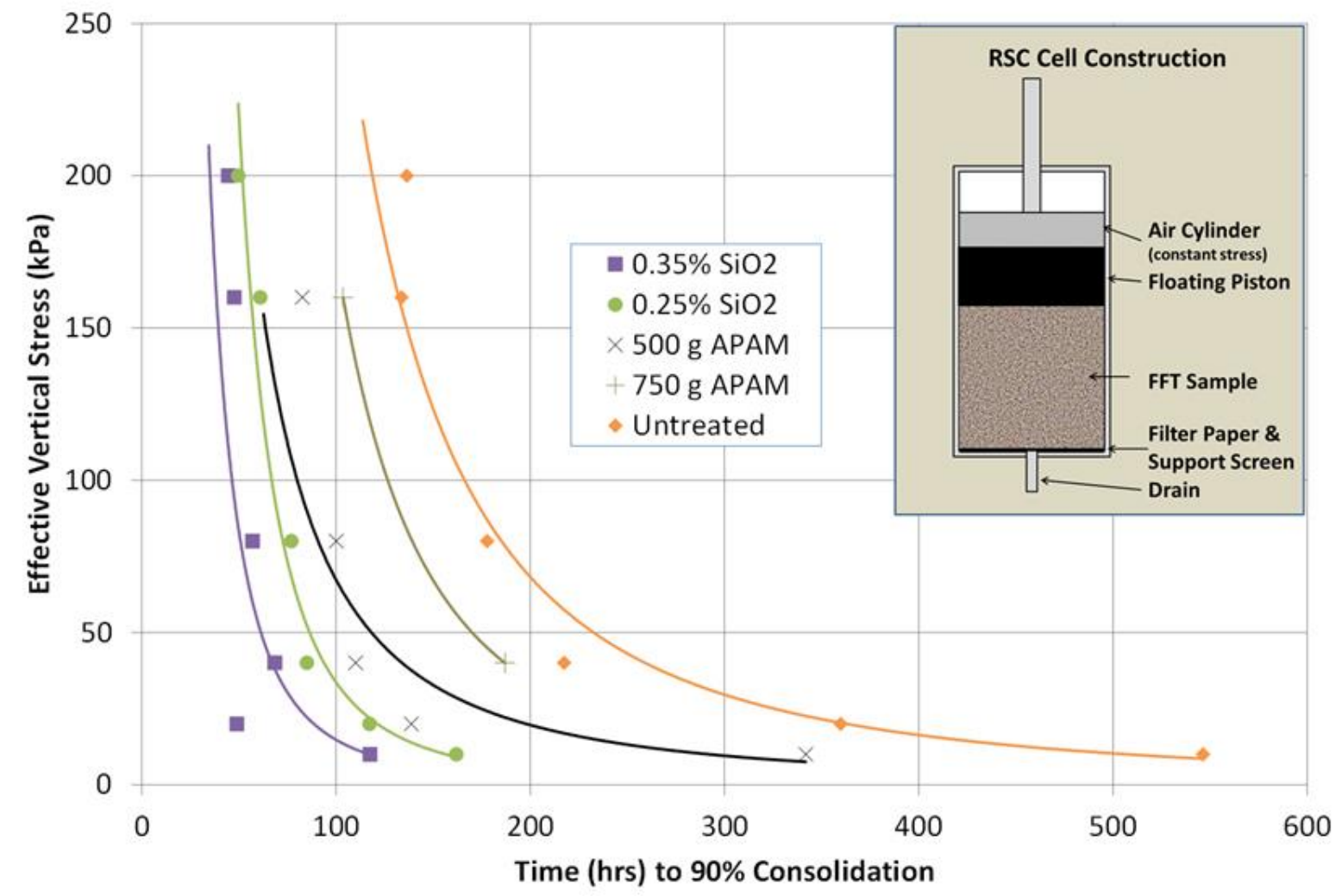

\section{Figure 10 Comparison of consolidation rates of untreated, silica treated and APAM treated MFT ' $A$ '}

\subsection{Fine particle mobility}

As described by Sobkowicz (2013), FFT particles are entrapped within the silica network thus preventing their movement. Immobilisation of fine particles would be anticipated to improve the function and life of installed drains or drainage boundaries. To demonstrate the ability to immobilise fine particles, MFT 'B' was treated with silica. It was then placed on a 40 mesh wire screen (420 micron opening between wires) in a compressive force dewatering cell $76 \mathrm{~mm}$ in diameter. A vertical stress of $3.5 \mathrm{kPa}$ was initially applied to the sample and then slowly ramped up to $69 \mathrm{kPa}$. The solids content of the release water was determined to be $105 \mathrm{ppm}$. Over $99.9 \%$ of the solid particles in the silica treated MFT did not pass through the 40 mesh screen with the release water. However, $100 \%$ of the particles in the untreated MFT would pass through the same 40 mesh screen.

\section{$4 \quad$ Field application}

\subsection{Tailings deposition profile}

A field trial was conducted in northern Alberta to demonstrate the ability to vary the deposition depth profile for silica treated MFT. $30 \mathrm{~m}^{3} / \mathrm{h}$ of MFT at $\sim 28 \mathrm{wt} \%$ solids were subjected to continuous silica treatment. The MFT was compositionally similar to MFT ' $B$ '. Figure 11 shows a $1.2 \mathrm{~m}$ deep deposit which generated an $8 \%$ slope whereas Figure 12 shows the same MFT being deposited in a thin lift approximately $10 \mathrm{~cm}$ thick which flowed over a distance of $80 \mathrm{~m}$ before the deposit flow was stopped by an earthen berm. The $1.2 \mathrm{~m}$ deep deposit shown in Figure 11 was generated using a relatively high silica dose and low shear conditions in the last $12 \mathrm{~m}$ of pipeline prior to deposition. The thin lift shown in Figure 12 was created under higher pipeline shear rates and an intermediate silica dose. 


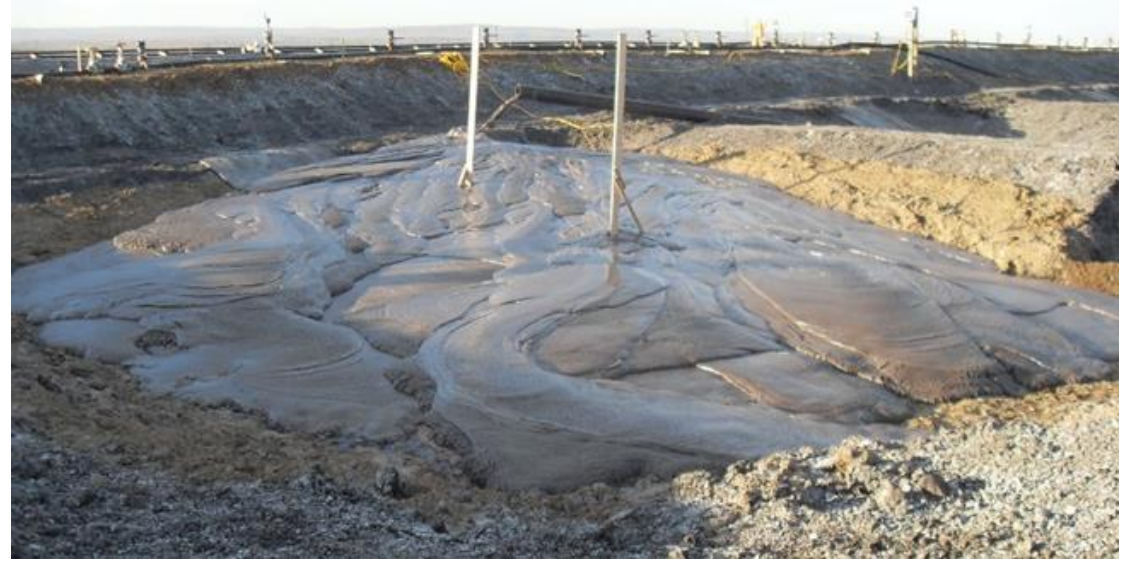

Figure 11 Field deposit of silica treated MFT demonstrating steep slope build

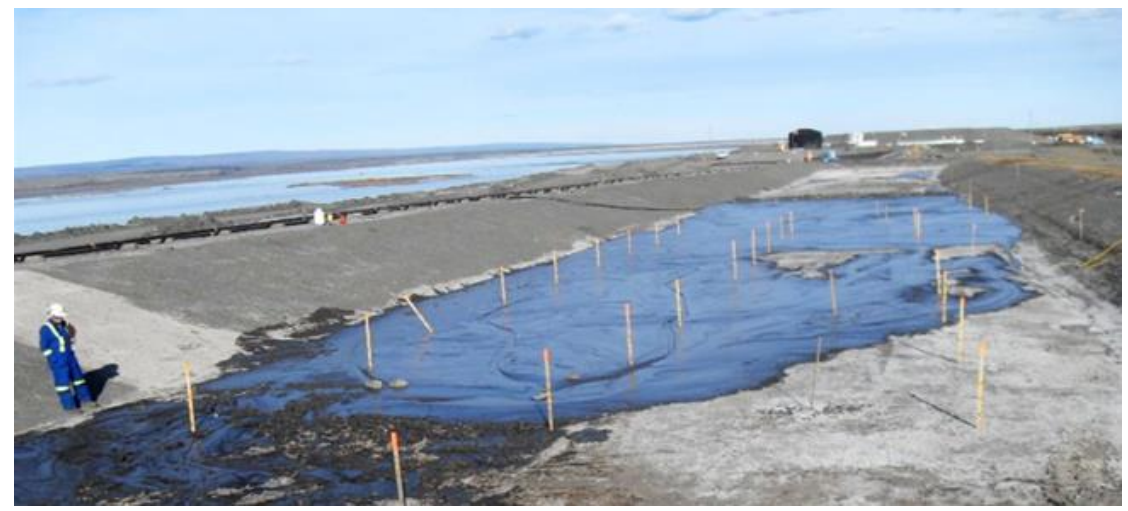

Figure 12 Field deposit of silica treated MFT demonstrating thin lift capability

A second field demonstration was conducted again in northern Alberta where $300 \mathrm{~m}^{3} / \mathrm{h}$ of MFT at $30 \mathrm{wt} \%$ solids was continuously treated with a low silica dose and high pipeline shear rate conditions. In this trial flow distances of over $300 \mathrm{~m}$ were demonstrated with a slope angle of $<0.5 \%$ build slope (Figure 13 ).

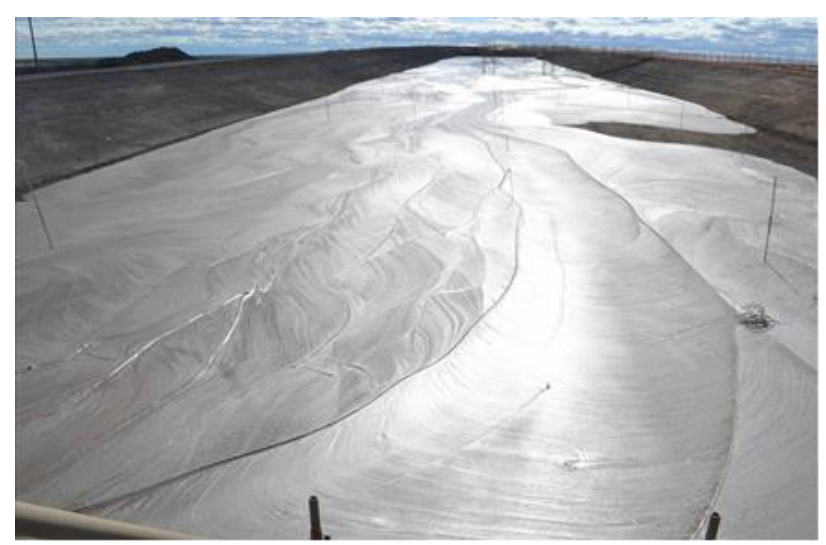

Figure 13 Field deposit of silica treated MFT demonstrating $>300$ m flow capability

\subsection{Thin lift deposition with evaporative drying}

As shown in Section 4.1 silica treated FFT has the ability to flow in relatively thin, continuous deposits which are highly desirable when conducting evaporative drying of FFT. Godbille (2014) has shown in the laboratory that FFT treated with silica has the same evaporative drying rate as a water filled reference pan. To assess the ability of thin lifts of silica treated MFT to evaporatively dry and gain strength in the field a demonstration was conducted in northern Alberta. The MFT used was again compositionally similar to MFT 
' $B$ ' having a solids concentration of approximately 28 wt\%. The MFT was treated with 0.5 wt\% silica and deposited in varying thicknesses on an impervious clay base. Core samples were taken over a 30-day period to determine solids concentration and peak yield strength at random depths beneath the surface of 20 and $30 \mathrm{~cm}$ thick deposits. Average potential evaporation during the test period was $4.7 \mathrm{~mm} /$ day. Figure 14 shows how the deposit transitions from a cracked to a pillared deposit surface. The solids concentration and yield strength of the deposit were seen to continually increase for the length of the study (Figure 14). At 28 days yield strengths within the $30 \mathrm{~cm}$ thick deposits ranged from $6-13 \mathrm{kPa}$ while the solids concentrations ranged between about 35-60 wt\%. This compares favourably with the $3 \mathrm{kPa}$ yield strength at 59 wt\% solids reported by Matthews (2011) for APAM flocculated MFT.
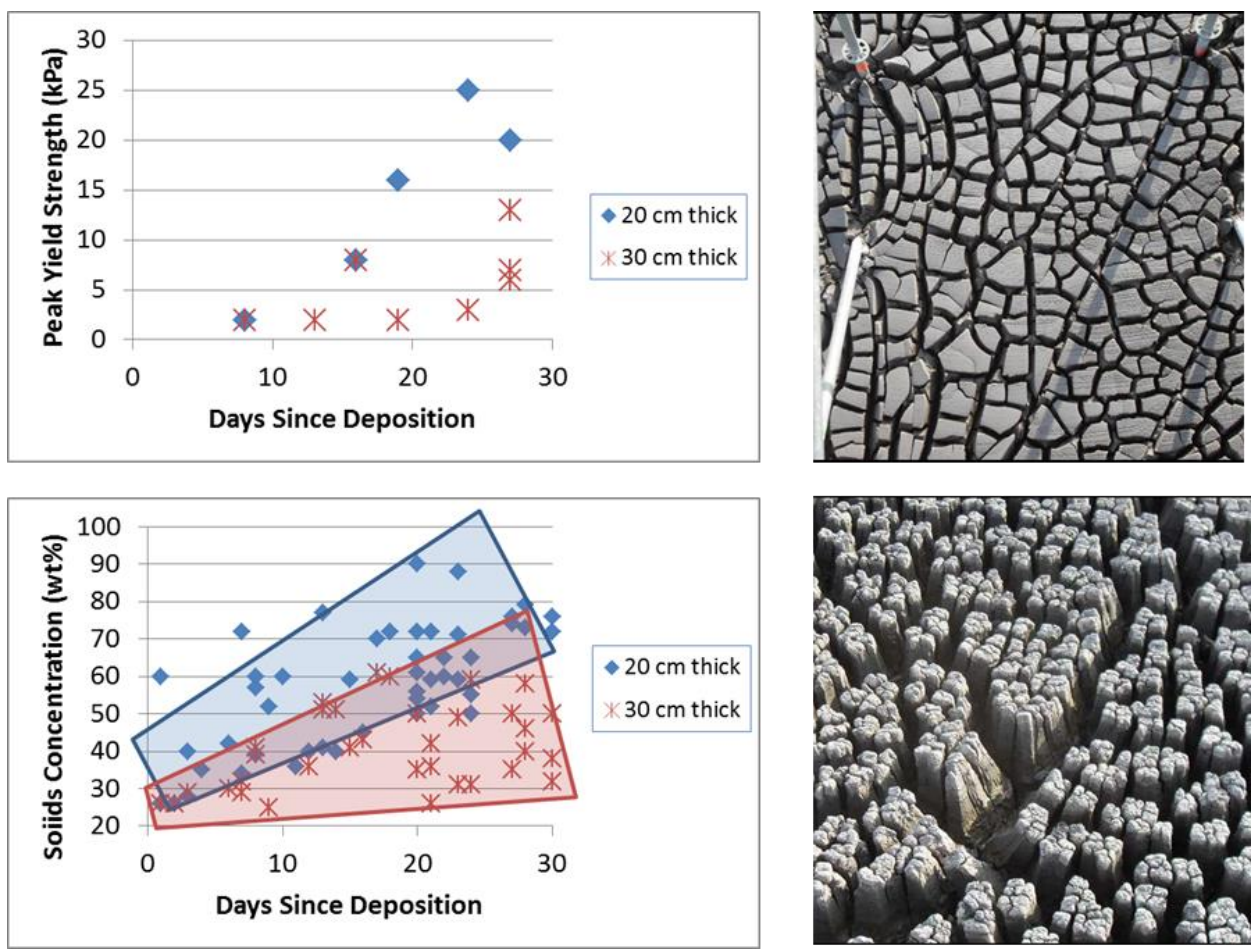

\section{Figure 14 Evaporative drying in field of silica treated MFT}

\subsection{Deep pit deposition with vertical stress dewatering}

Evaporative drying of FFT deposits may not be practical depending upon climatic conditions. In these instances, deep pit deposition may be a preferred alternative. To demonstrate the ability of silica treated FFT to dewater under a small surcharge load (compressive force) northern Alberta MFT at $30 \mathrm{wt} \%$ solids and compositionally similar to MFT ' $\mathrm{B}$ ' was treated with $0.5 \mathrm{wt} \%$ silica. The treated MFT was placed in a $2.4 \times 2.4 \times 1.2 \mathrm{~m}$ deep perforated container lined with sand. 24 hours after filling the container a layer of sand was placed on top of the silica treated MFT followed by a plywood lid to protect the MFT during surcharge loading. Enough overburden was placed on top of the lid to achieve approximately $12 \mathrm{kPa}$ vertical effective stress.

The height of the deposit was monitored for approximately one year during which time the MFT height was reduced by $42 \%$. A $30 \%$ reduction in height occurred in only 41 days after the surcharge was applied. Core samples were removed from the container after one year. Average solids concentration and peak yield strength values at different depths within the deposit are shown in Figure 15. 
End of Fill

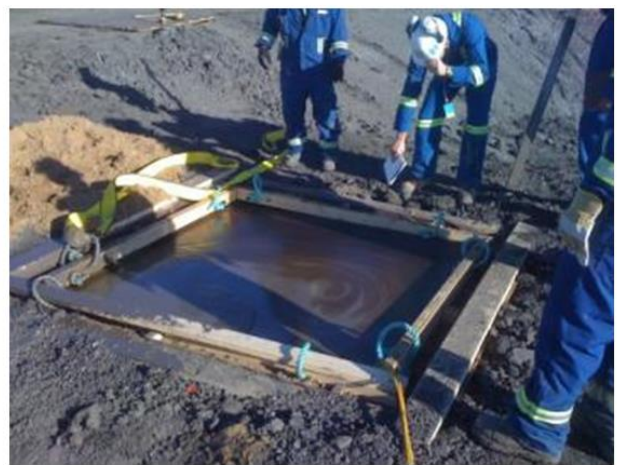

Field Consolidation Rate

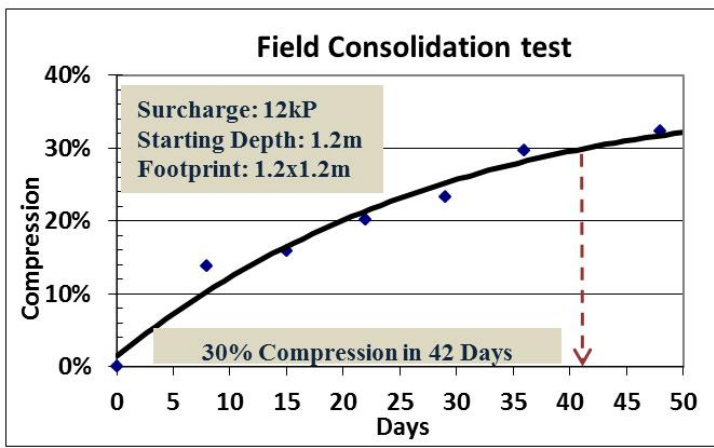

One Year After Fill

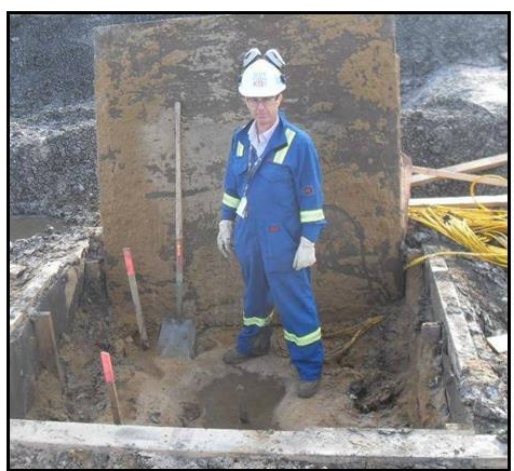

Solids Conc. and Yield Strength @ 1 Year

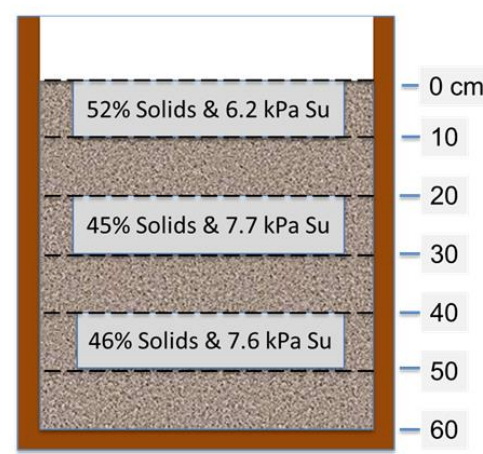

\section{Figure 15 Field demonstration of vertical stress dewatering}

\subsection{Capping of soft tailings deposits}

Silica treatment has the potential to be used as a means to simplify the installation of cover systems over soft tailings deposits. Placement of a 'flowable' cap is operationally less complex and significantly safer than placement of geotextiles or solid overburden over soft tailings. Treated tailings material can be pumped overtop of soft deposit, keeping personnel and equipment safely onshore. The 'flowability', cap contour and the treated tailings' final strength can all be controlled with dose and activator choice to meet specific design criteria. With a much stronger support layer in place, addition of traditional cover materials could then be placed using conventional methods.

An example of how silica treated FFT might be used to generate a high-strength cap is shown in Figure 16. In this field demonstration MFT at $28 \mathrm{wt} \%$ solids MFT was treated with $1.2 \mathrm{wt} \% \mathrm{SiO}$. The calculated yield strength for the deposit was approximately $5 \mathrm{kPa}$ two days after deposition in northern Alberta during early autumn. 


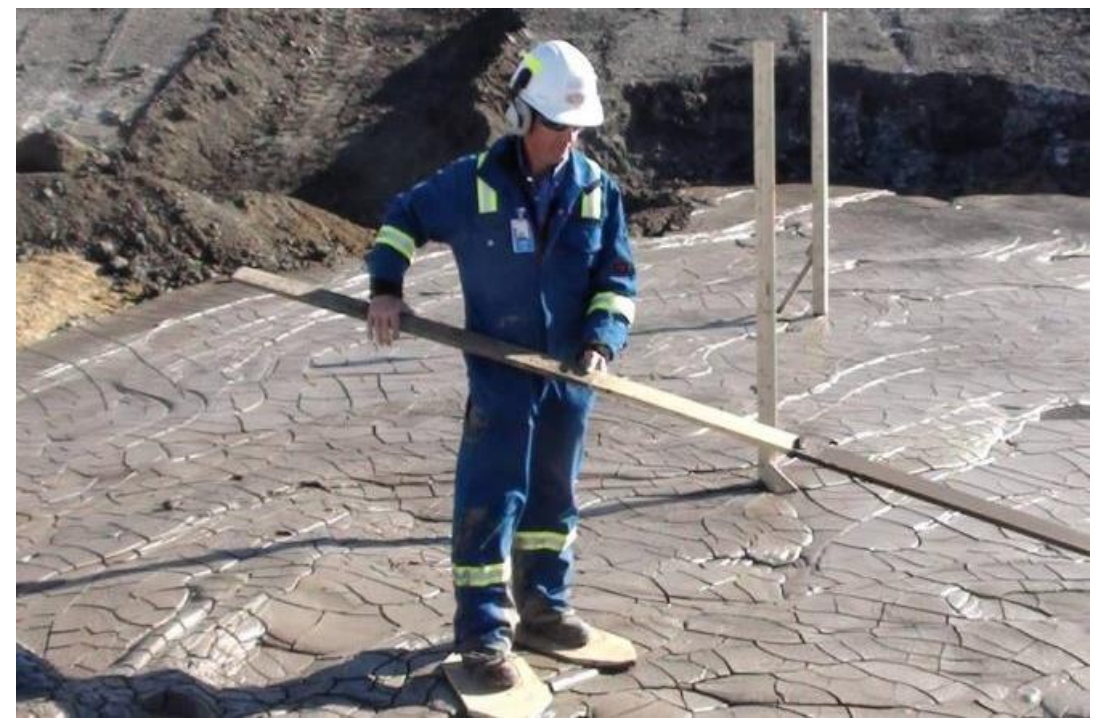

\section{Figure 16 Field demonstration of high-strength capping deposit}

\section{Conclusions}

In situ polymerisation of silica (Particlear ${ }^{\mathrm{TM}}$ ) offers a completely different approach to treatment of FFT than the use of traditional flocculants. Silica treatment has the ability to modify and control FFT rheology in order to create deposits that can flow over long distances with resulting gentle slopes, or to create deposits that flow for only short distances and generate steep slopes. FFT treated with silica has substantially higher yield strength than the same FFT treated with APAM. Particlear ${ }^{\mathrm{TM}}$ treated FFT retains much more of its strength than APAM treated FFT when the treated FFT is subjected to shear. FFT solids are immobilised by the silica treatment helping to protect drains and drainage boundaries from blinding by mobile fine particles. Silica treatment reduces FFT compressibility while maintaining hydraulic conductivity thus resulting in faster FFT consolidation rates. Evaporative drying or dewatering through vertical stress can both be successfully employed with silica treated FFT. Particlear ${ }^{\mathrm{TM}}$ treatment offers a new method to create a high-strength, 'flowable' cap over soft tailings deposits to facilitate earlier site reclamation.

\section{References}

Brookfield Engineering n.d., Rheocalc, Brookfield Engineering Laboratories, Inc., Middleboro, http://www.brookfieldengineering.com /products/software/rheocalc.asp.

Godbille, FD 2014, 'Modification of fluid fine tailing's rheological and stacking properties by in situ silica polymerisation', in RJ Jewell, AB Fourie, PS Wells \& D van Zyl (eds), Proceedings of the 17th International Seminar on Paste and Thickened Tailings, InfoMine Inc., Vancouver, pp. 201-214.

Karol, R 2003, Chemical Grouting and Soil Stabilization, 3rd edn, Marcel Dekker, Inc., New York.

Matthews, JG 2011, Field trials of thin-lift deposition of amended mature fine tailings at the Muskeg River Mine in Northern Alberta, in RJ Jewell \& AB Fourie (eds), Proceedings of the 14th International Seminar on Paste and Thickened Tailings, Australian Centre for Geomechanics, Perth, pp. 271-280.

Moffett, RH 2010, 'Treatment of fluid fine tailings with silica', Proceedings of the 14th Annual Conference on Tailings and Mine Waste, CRC Press, Leiden, pp. 347-353.

Moore, T 2013, 'Laboratory investigation of the large strain consolidation behaviour of oil sands fluid fine tailings treated with DuPont Particlear ${ }^{\mathrm{TM}}$ ', Proceedings of the 66th Annual Canadian Geotechnical Conference, paper number 528.

Sobkowicz, JC 2013, 'Predictive model for thick lift placement of silica-treated fluid fine tailings', in GW Wilson, DC, Sego, NA Beier (eds), Proceedings of the 17th Annual Conference on Tailings and Mine Waste, pp. 181-189.

Tilton, JN 2013, 'Preferred rheological attributes for deposition of tailings slurries', in GW Wilson, DC, Sego, NA Beier (eds), Proceedings of the 17th Annual Conference on Tailings and Mine Waste, pp. 181-189. 